\title{
Fe-Rich Soft Magnetic FeSiBPCu Hetero-Amorphous Alloys with High Saturation Magnetization
}

\author{
Men $\mathrm{He}^{1, * 1}$, Liying Cui ${ }^{1,2, * 2}$, Takeshi Kubota ${ }^{3}$, Kunio Yubuta ${ }^{3}$, \\ Akihiro Makino ${ }^{3}$ and Akihisa Inoue ${ }^{3}$ \\ ${ }^{1}$ Graduate School of Material Science and Engineering, Tohoku University, Sendai 980-8577, Japan \\ ${ }^{2}$ School of Materials Science and Engineering, Dalian University of Technology, Dalian 116024, P.R. China \\ ${ }^{3}$ Institute for Materials Research, Tohoku University, Sendai 980-8577, Japan
}

\begin{abstract}
Magnetic properties are perhaps the most remarkable and unique properties of Fe-based amorphous alloys. To obtain high saturation magnetization, high Fe content is preferred. However, there is a strict upper limit of Fe content for the formation of a single amorphous structure with good magnetic softness. Fe-based amorphous alloys with high Fe content over the limit have an as-quenched structure consisting of coarse $\alpha$-Fe grains in an amorphous matrix, which inevitably results in inferior magnetic softness. We have studied the effect of $\mathrm{P}$ and/or $\mathrm{Cu}$ additions on the microstructure of Fe-based amorphous alloys with high Fe content. The $\alpha$-Fe grain size and the coercivity $\left(H_{\mathrm{c}}\right)$ decrease by the simultaneously adding $\mathrm{P}$ and $\mathrm{Cu}$. The Fe-rich FeSiBPCu alloys with the optimized composition have an extremely small $\alpha$-Fe-like phase of about $3 \mathrm{~nm}$ or smaller in a diameter, exhibits the higher $J_{\mathrm{s}}$ of about $1.67 \mathrm{~T}$ than that of the typical Fe-based amorphous alloy and show the low coercivity $\left(H_{\mathrm{c}}\right)$ of about $4 \mathrm{Am}^{-1}$ in an as-quenched state. [doi:10.2320/matertrans.ME200831]
\end{abstract}

(Received December 19, 2008; Accepted April 8, 2009; Published May 20, 2009)

Keywords: soft magnetic alloys, iron-based amorphous alloys, hetero-amorphous alloys, high saturation magnetization

\section{Introduction}

The silicon steel (Fe-3.5 mass\% Si crystalline alloy $)^{1)}$ has occupied the largest market share in the soft magnetic material field due to the high saturation magnetization $\left(J_{\mathrm{s}}\right)$ of about $2 \mathrm{~T}$ and the low material cost. However, the silicon steel exhibits inferior magnetic softness which is resulted from the large magnetocrystalline anisotropy. The Fe-based amorphous and hetero-amorphous alloys ${ }^{2-8)}$ shows low intrinsic magnetocrystalline anisotropy and therefore are regarded as substitutes for the silicon steel in the future applications. Consequently great efforts have been devoted to develop Fe-based amorphous and hetero-amorphous alloys with lower material cost, higher productivity, ${ }^{9-11)}$ better soft magnetic properties and higher $J_{\mathrm{s}} \cdot{ }^{12-15)}$

In order to obtain high $J_{\mathrm{s}}$, high Fe content is required for the Fe-based amorphous and hetero-amorphous alloys. However, there is a strict upper limit of the Fe content for forming amorphous phase with good magnetic softness. The alloys with a $\mathrm{Fe}$ content exceeding 80 at $\%$ have an asquenched structure consisting of coarse $\alpha$-Fe grains and amorphous matrix. These coarse $\alpha$-Fe grains inevitably result in inferior magnetic softness. It has been reported that the additions of $\mathrm{P}$ and $\mathrm{Cu}$ can refine the coarse $\alpha$-Fe grains and enable the formation of amorphous $\mathrm{FeNbBPCu}$ alloy with good magnetic softness and high $J_{\mathrm{S}}{ }^{12,16)}$ In this paper we further studied the effect of $\mathrm{P}$ and $\mathrm{Cu}$ additions on the structure and properties of FeSiBPCu. The new FeSiBPCu hetero-amorphous alloys with optimized $\mathrm{P}$ and $\mathrm{Cu}$ additions exhibit a unique combination of good soft magnetic property and high $J_{\mathrm{s}}$.

\footnotetext{
${ }^{* 1}$ Graduate Student, Tohoku University

${ }^{* 2}$ Graduate Student, Dalian University of Technology \& Graduate Student, Tohoku University
}

\section{Experimental Procedure}

Alloy ingots were prepared by arc-melting of $\mathrm{Fe}$ (99.98 mass\%), Si (99.98 mass\%), B (99.5 mass\%), Cu (99.99 mass\%) and pre-alloyed Fe-P (99.9 mass\%) in a purified argon atmosphere. Rapidly solidified ribbons were produced by a single-roller melt-spinning method in air. The prepared ribbons were about $2 \mathrm{~mm}$ in width and $20 \mu \mathrm{m}$ in thickness. The structure of the as-quenched ribbons was identified by $\mathrm{X}$-ray diffraction (XRD) with $\mathrm{Cu}-\mathrm{K}_{\alpha}$ radiation and transmission electron microscopy (TEM). The coarse $\alpha$ Fe grain size was estimated by Scherrer equation from the full width at half maximum of the bcc $\{110\}$ reflection peak from $\alpha$-Fe phase. The coercivity $\left(H_{\mathrm{c}}\right)$ under a maximum applied field of $10 \mathrm{kAm}^{-1}$ was measured by a dc B-H loop tracer with the accuracy of $0.1 \mathrm{Am}^{-1}$. The $J_{\mathrm{s}}$ under a maximum applied field of $800 \mathrm{kAm}^{-1}$ were measured by vibrating sample magnetometer (VSM). The density of the as-quenched ribbons was measured by Archimedean method with n-tridecane. All the property measurements were carried out at room temperature.

\section{Results and Discussion}

Figure 1 shows the XRD patterns of the as-quenched FeSiBPCu ribbons. The alloy without $\mathrm{P}$ and $\mathrm{Cu}$ additions exhibit a broad diffraction hump consisted with a sharp peak corresponding to $\alpha-\mathrm{Fe}$. According to the Scherrer equation, the mean grain size of the $\alpha$-Fe phase is determined to be about $93 \mathrm{~nm}$. The diffraction peak disappears with the simultaneous additions of $\mathrm{P}$ and $\mathrm{Cu}$ in $\mathrm{Fe}_{81.7} \mathrm{~B}_{7} \mathrm{Si}_{9} \mathrm{P}_{2} \mathrm{Cu}_{0.3}$, $\mathrm{Fe}_{83.3} \mathrm{Si}_{4} \mathrm{~B}_{8} \mathrm{P}_{4} \mathrm{Cu}_{0.7}, \mathrm{Fe}_{84.3} \mathrm{Si}_{4} \mathrm{~B}_{8} \mathrm{P}_{3} \mathrm{Cu}_{0.7}$ and $\mathrm{Fe}_{85.3} \mathrm{Si}_{2} \mathrm{~B}_{10^{-}}$ $\mathrm{P}_{2} \mathrm{Cu}_{0.7}$ alloys. It can be seen that the simultaneous additions of $\mathrm{P}$ and $\mathrm{Cu}$ play an important role on the structure improvement. Amorphous structure (in XRD scale) can be obtained in the FeSiBPCu alloys even with a Fe content exceeding the upper limit of 80 at $\%$. 


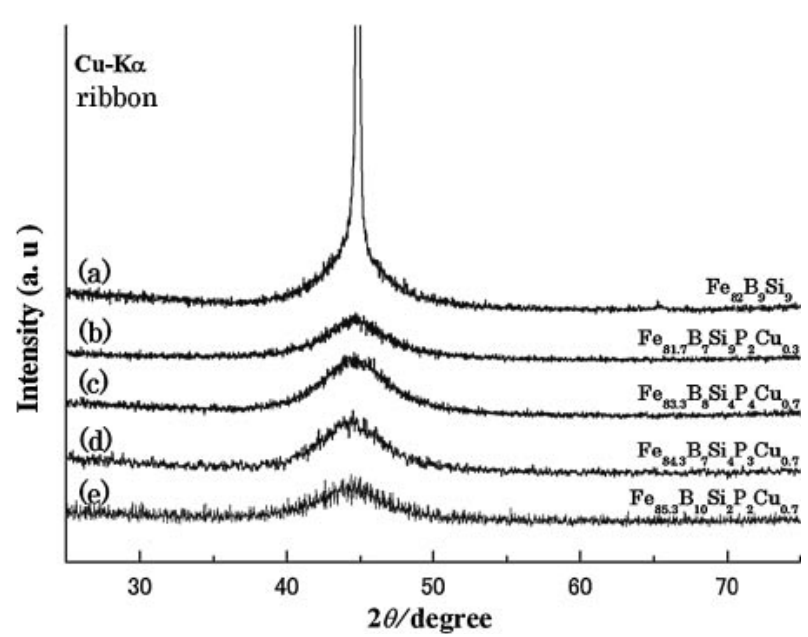

Fig. 1 XRD diffraction pattern for the as-quenched $\mathrm{Fe}_{82} \mathrm{~B}_{9} \mathrm{Si}_{9}, \mathrm{Fe}_{81.7} \mathrm{~B}_{7}$ $\mathrm{Si}_{9} \mathrm{P}_{2} \mathrm{Cu}_{0.3}, \mathrm{Fe}_{83.3} \mathrm{Si}_{4} \mathrm{~B}_{8} \mathrm{P}_{4} \mathrm{Cu}_{0.7}, \mathrm{Fe}_{84.3} \mathrm{Si}_{4} \mathrm{~B}_{8} \mathrm{P}_{3} \mathrm{Cu}_{0.7}$ and $\mathrm{Fe}_{85.3} \mathrm{Si}_{2} \mathrm{~B}_{10^{-}}$ $\mathrm{P}_{2} \mathrm{Cu}_{0.7}$ ribbons.

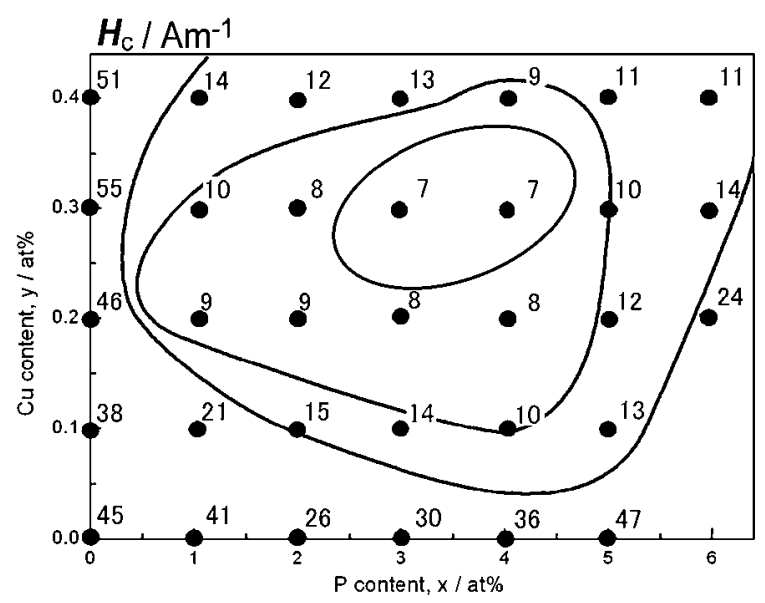

Fig. 2 Compositional dependence of $H_{\mathrm{c}}$ on $\mathrm{P}$ and $\mathrm{Cu}$ contents for asquenched $\mathrm{Fe}_{82-y} \mathrm{Si}_{9} \mathrm{~B}_{9-x} \mathrm{P}_{x} \mathrm{Cu}_{y}(x=0 \sim 6, y=0 \sim 0.4)$ ribbons.

Figure 2 presents the composition dependence of $H_{\mathrm{c}}$ on $\mathrm{P}$ and $\mathrm{Cu}$ for the as-quenched $\mathrm{Fe}_{82-y} \mathrm{Si}_{9} \mathrm{~B}_{9-x} \mathrm{P}_{x} \mathrm{Cu}_{y}(x=0 \sim 6$, $y=0 \sim 0.4$ ) alloys. The alloy without $\mathrm{P}$ and $\mathrm{Cu}$ additions shows the largest $H_{\mathrm{c}}$ value of $45 \mathrm{Am}^{-1}$, which is due to the existence of the coarse $\alpha$-Fe crystals as evidenced form the XRD pattern in Fig. 1. The $H_{\mathrm{c}}$ decreases with the additions of $\mathrm{P}$ and $\mathrm{Cu}$. The minimum $H_{\mathrm{c}}$ value of $7 \mathrm{Am}^{-1}$ appears at the composition vicinity with $3 \sim 4 \% \mathrm{P}$ and $0.3 \% \mathrm{Cu}$. Since the proper amount of $\mathrm{P}$ and $\mathrm{Cu}$ additions dramatically decrease the $H_{\mathrm{c}}$ of as-spun $\mathrm{Fe}_{82-y} \mathrm{Si}_{9} \mathrm{~B}_{9-x} \mathrm{P}_{x} \mathrm{Cu}_{y}$ alloys, one may expect the formation of amorphous or hetero-amorphous FeSiB alloys with both low $H_{\mathrm{c}}$ and high $J_{\mathrm{s}}$ (high Fe content) by $\mathrm{P}$ and $\mathrm{Cu}$ additions. Therefore the simultaneous additions of $\mathrm{P}$ and $\mathrm{Cu}$ were performed on the alloys with higher Fe content. Figure 3 shows the composition dependence of $H_{\mathrm{c}}$ on the $\mathrm{Fe}$ content. It is clearly that the $\mathrm{P}$ and $\mathrm{Cu}$ additions are also effective to decrease the $H_{\mathrm{c}}$ for the alloys with extremely high Fe content. Even the as-quenched $\mathrm{Fe}_{85.3} \mathrm{Si}_{2} \mathrm{~B}_{10} \mathrm{P}_{2} \mathrm{Cu}_{0.7}$ alloy exhibit a much lower $H_{\mathrm{c}}$ of $4 \mathrm{Am}^{-1}$ than that of $\mathrm{Fe}_{82} \mathrm{~B}_{9} \mathrm{Si}_{9}$.

To exhaust the reason that why the simultaneous additions of $\mathrm{P}$ and $\mathrm{Cu}$ lead to the dramatic decrease in $H_{\mathrm{c}}$, the local structure of the as-spun $\mathrm{Fe}_{81.7} \mathrm{~B}_{7} \mathrm{Si}_{9} \mathrm{P}_{2} \mathrm{Cu}_{0.3}$ and $\mathrm{Fe}_{85.3} \mathrm{Si}_{2}-$

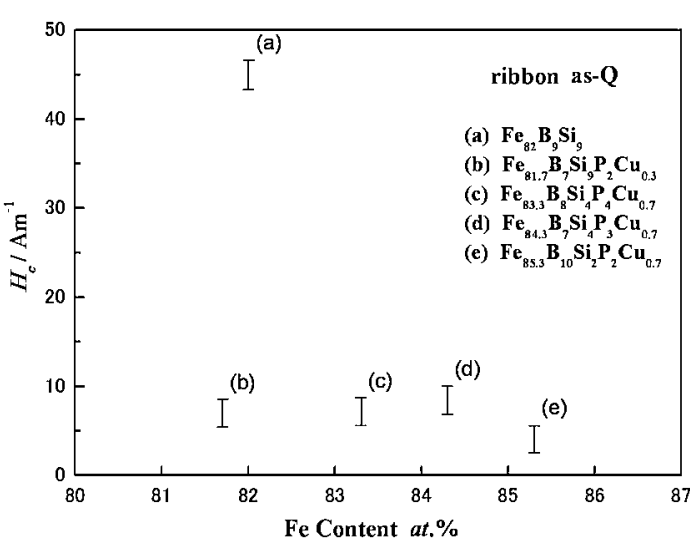

Fig. 3 Compositional dependence of $H_{\mathrm{c}}$ on $\mathrm{Fe}$ content for as-quenched $\mathrm{Fe}_{82} \mathrm{~B}_{9} \mathrm{Si}_{9}, \mathrm{Fe}_{81.7} \mathrm{~B}_{7} \mathrm{Si}_{9} \mathrm{P}_{2} \mathrm{Cu}_{0.3}, \mathrm{Fe}_{83.3} \mathrm{Si}_{4} \mathrm{~B}_{8} \mathrm{P}_{4} \mathrm{Cu}_{0.7}, \mathrm{Fe}_{84.3} \mathrm{Si}_{4} \mathrm{~B}_{8} \mathrm{P}_{3} \mathrm{Cu}_{0.7}$ and $\mathrm{Fe}_{85.3} \mathrm{Si}_{2} \mathrm{~B}_{10} \mathrm{P}_{2} \mathrm{Cu}_{0.7}$ ribbons.

$\mathrm{B}_{10} \mathrm{P}_{2} \mathrm{Cu}_{0.7}$ alloys were investigated by TEM. The HRTEM images and the selected area electron diffraction (SAED) patterns of the two alloys are shown in Fig. 4 and Fig. 5, respectively. The rather sharp SAED patterns suggest the existence of nanocrystals in the as-quenched $\mathrm{Fe}_{81.7} \mathrm{~B}_{7} \mathrm{Si}_{9}$ $\mathrm{P}_{2} \mathrm{Cu}_{0.3}$ and $\mathrm{Fe}_{85.3} \mathrm{Si}_{2} \mathrm{~B}_{10} \mathrm{P}_{2} \mathrm{Cu}_{0.7}$ alloys. The HRTEM images further confirm the formation of homogenously dispersed $\alpha$ Fe crystals. Due to the small size (about $3 \mathrm{~nm}$ ), these $\alpha$-Fe nanocrystals cannot be identified by XRD. These results indicate that the simultaneous additions of $\mathrm{P}$ and $\mathrm{Cu}$ play an important role on refining the $\alpha$-Fe crystals for the FeSiB alloys. The significant effect of the refining may be related to the mixing enthalpy between the constituent elements. A repulsive interaction exists between $\mathrm{Fe}$ and $\mathrm{Cu}$ atoms due to the positive mixing enthalpy $(13 \mathrm{~kJ} / \mathrm{mol})$ between them. On the other hand, an attractive interaction exists between $\mathrm{Cu}$ and $\mathrm{P}$ atoms due to the negative mixing enthalpy $(-9 \mathrm{~kJ} / \mathrm{mol})$. Once these adverse interactions between these elements form, P-rich and $\mathrm{Cu}$-rich regions can be dispersed in the FeSiB amorphous matrix and form nucleation sites for $\alpha$ $\mathrm{Fe}$ during cooling. Thus the $\mathrm{P}$ and $\mathrm{Cu}$ additions can improve the microstructure of the as-quenched $\mathrm{FeSiB}$ alloys and therefore lead to lower $H_{\mathrm{c}}$. Such similar effect has also been found in FeNbB alloys. ${ }^{13}$ )

As described above, by the simultaneous additions of $\mathrm{P}$ and $\mathrm{Cu}$, hetero-amorphous $\mathrm{FeSiB}$ alloys with extremely high $\mathrm{Fe}$ content can be developed, which provides the possibility to produce Fe-based alloys with both low $H_{\mathrm{c}}$ and high $J_{\mathrm{s}}$. Consequently the $J_{\mathrm{s}}$ of the as-spun FeSiBPCu ribbons were measured. Figure 6 presents the $J-H$ curves of the as-quenched $\mathrm{Fe}_{84.3} \mathrm{Si}_{4} \mathrm{~B}_{8} \mathrm{P}_{3} \mathrm{Cu}_{0.7}, \mathrm{Fe}_{85.3} \mathrm{Si}_{2} \mathrm{~B}_{10} \mathrm{P}_{2} \mathrm{Cu}_{0.7}$ and $\mathrm{F}_{78} \mathrm{Si}_{9} \mathrm{~B}_{13}$ ribbons, from where the $J_{\mathrm{s}}$ of the three alloys are determined to be $1.67 \mathrm{~T}, 1.58 \mathrm{~T}$, and $1.49 \mathrm{~T}$, respectively. It is clear that the $\mathrm{FeSiBPCu}$ alloys with higher Fe content has a lower $J_{\mathrm{s}}$.

\section{Conclusions}

The effects of the simultaneous additions of $\mathrm{P}$ and $\mathrm{Cu}$ on the microstructure and magnetic properties were investigated for the as-quenched $\mathrm{FeSiB}(\mathrm{PCu})$ alloys with high $\mathrm{Fe}$ content exceeding the limit for the formation of a single amorphous phase. 


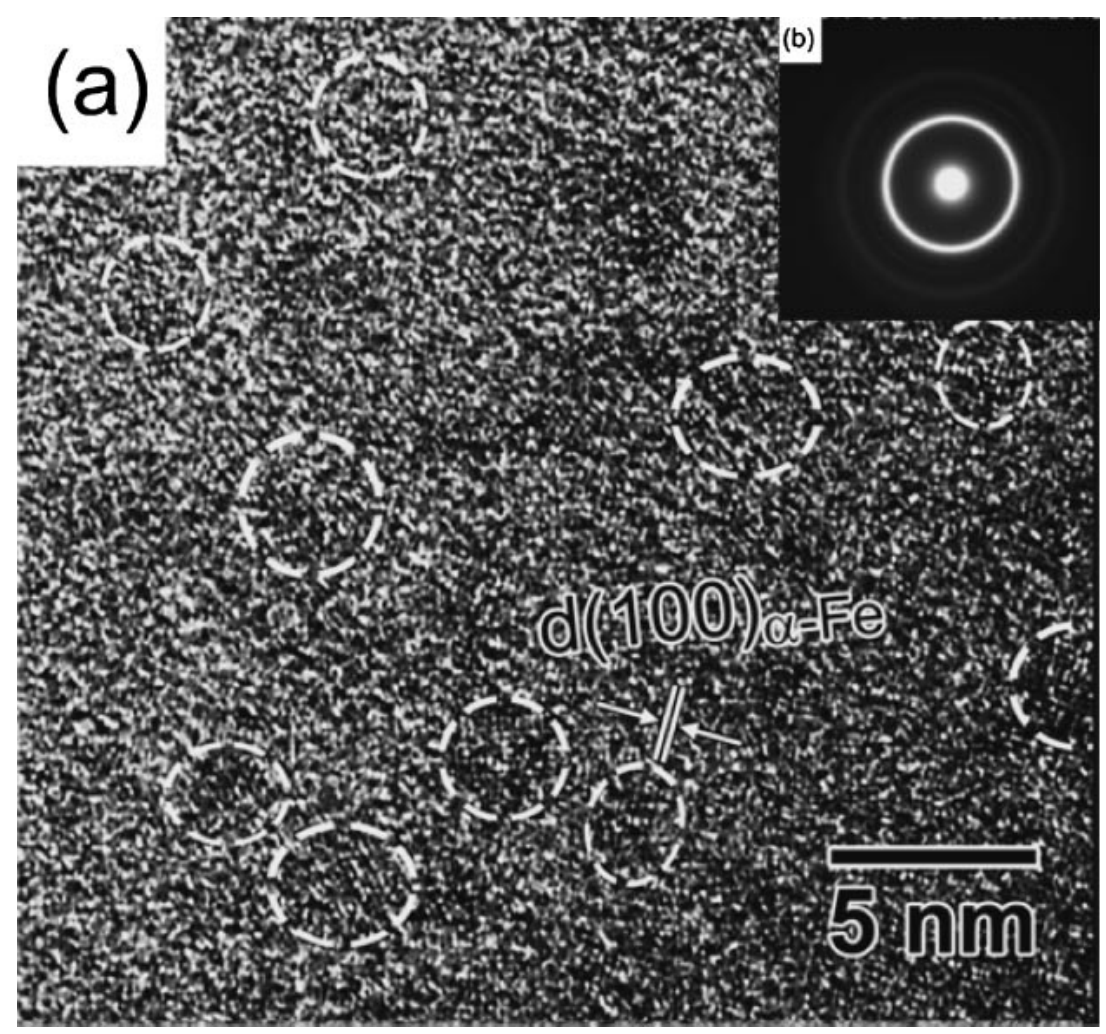

Fig. 4 HRTEM image (a) and SAED pattern (b) of the as-quenched $\mathrm{Fe}_{81.7} \mathrm{~B}_{7} \mathrm{Si}_{9} \mathrm{P}_{2} \mathrm{Cu}_{0.3}$ ribbon.

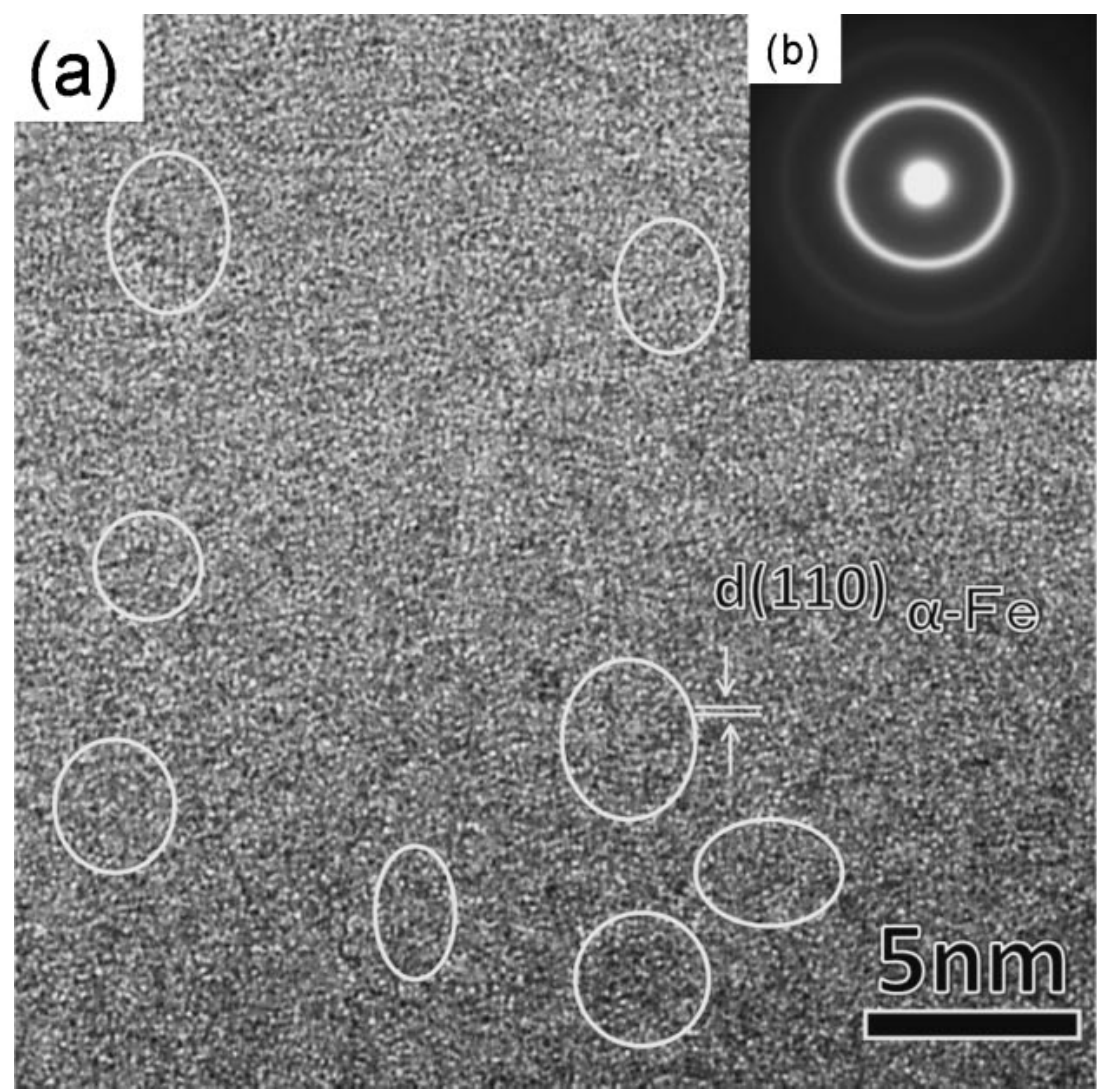

Fig. 5 HRTEM image and SAED pattern of the as-quenched $\mathrm{Fe}_{85.3} \mathrm{Si}_{2} \mathrm{~B}_{10} \mathrm{P}_{2} \mathrm{Cu}_{0.7}$ ribbon. 


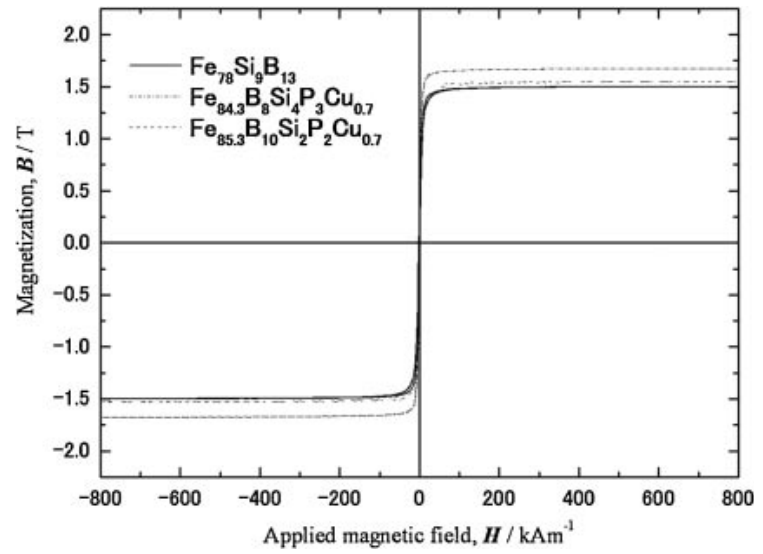

Fig. $6 J-H$ curve of as quenched $\mathrm{Fe}_{84.3} \mathrm{Si}_{4} \mathrm{~B}_{8} \mathrm{P}_{3} \mathrm{Cu}_{0.7}, \mathrm{Fe}_{85.3} \mathrm{Si}_{2} \mathrm{~B}_{10} \mathrm{P}_{2} \mathrm{Cu}_{0.7}$ and $\mathrm{F}_{78} \mathrm{Si}_{9} \mathrm{~B}_{13}$ ribbons.

(1) The simultaneous additions of $\mathrm{P}$ and $\mathrm{Cu}$ decrease the grain size of the $\alpha$-Fe in the as-quenched $\mathrm{FeSiB}$ alloys from 93 to about $3 \mathrm{~nm}$.

(2) The $H_{\mathrm{c}}$ of as-quenched FeSiBPCu alloy decreases from 45 to $4 \mathrm{Am}^{-1}$ which is resulted from the refinement of $\alpha$-Fe phase in the as-quenched alloys.

(3) The FeSiBPCu alloy with an extremely high Fe content of 84.3 at $\%$ exhibits high $J_{\mathrm{s}}$ value of $1.67 \mathrm{~T}$.

\section{REFERENCES}

1) F. E. Luborsky, J. J. Becker, P. G. Frischmann and L. A. Johnson: J. Appl. Phys. 49 (1978) 1769-1774.

2) M. Hayashide, S. Ohnuma, F. Matsumoto, H. Fujimori and T. Masumoto: IEEE Trans. Magn. 7 (1992) 306-310.

3) A. Inoue and A. Makino: Nanostruct. Mater. 9 (1997) 403-412.

4) A. Inoue and W. Zhang: J. Appl. Phys. 85 (1999) 4491-4493.

5) A. Makino, A. Inoue and T. Masumoto: Nanostruct. Mater. 12 (1999) $825-828$.

6) H. Chiriac, N. Lupu and M. Tibu: IEEE Trans. Magn. 39 (2003) 30403042 .

7) A. Makino, T. Bitoh, A. Inoue and T. Masumoto: Scr. Mater. 48 (2003) 869-874.

8) A. Inoue, B. L. Shen and C. T. Chang: Acta Mater. 52 (2004) 40934099.

9) T. Yamaguchi and K. Narita: IEEE Trans. Magn. 13 (1977) 1621-1623.

10) F. E. Luborsky, J. J. Becker, J. L. Walter and H. H. Liebermann: IEEE Trans. Magn. 3 (1979) 1146-1149.

11) M. Mitera, T. Masumoto and N. S. Arakawa: J. Appl. Phys. 50 (1979) 7609-7611.

12) M. Mitera, M. Naka, T. Masumoto and N. S. Kazama: Phys. Status Solidi A 49 (1978) 163-166.

13) A. Makino, M. Bingo, T. Bitoh, K. Yubuta and A. Inoue: J. Appl. Phys. 101 (2007) 09N117-3.

14) A. Makino, T. Kubota, C. Chang, M. Makabe and A. Inoue: J. Magn. Magn. Mater. 320 (2008) 2499-2503.

15) A. Makino, T. Kubota, M. Makabe, C. T. Chang and A. Inoue: Mater. Sci. Eng. B 148 (2008) 166-170.

16) A. Makino, X. Li, K. Yubuta, C. Chang, T. Kubota and A. Inoue: Scr. Mater. 60 (2009) 277-280. 